\title{
ANTHROPOMETRIC STUDY ON HAND AND ITS DIGITAL PRINTS FOR DETERMINATION OF SEX IN AN EGYPTIAN POPULATION SAMPLE
}

\author{
Nadia kotb, Saied Abul-Nasr, Mona M Ali and Fatma Nada \\ Forensic medicine and clinical toxicology department, Cairo University
}

\begin{abstract}
:
Background: Positive identification of the deceased is one of the main aims in any forensic medicolegal investigation. This is extremely difficult when collection of bones or dismembered remains is brought for examination. In these situations, the primary aim of investigation is to determine the age, sex, race and physical features. So as to eliminate these difficulties, new methods are being developed. The aim of this study: is to develop formulae for determination of the sex through hand measurements and digital print parameters and compare the accuracy of both methods. Material and methods: the hand (length and width), palm length and the four digit length measurements of the right hand were taken from right hand of the 160 adults ( 80 males and 80 females) and from their digital prints. Results of the study showed that males had larger hand dimensions than females in both anthropometric and print measures. .To determine sex from hand measures and digital print parameters in both groups, a logistic regression was done to create regression equation. The accuracy of sex determination by this equation was very high reaching 79. \%. Conclusion: Formulae were obtained by the logistic regression analysis for from both anthropometric measures and digital print parameters showing higher accuracy for anthropometric method. Recommendations: using the anthropometric measurements in determination of sex from hand as the print method is less accurate, future research works are required to increase the accuracy of print method.
\end{abstract}

\section{INTRODUCTION:}

The most important stages in identity determination are stature and sex determination. They are easily done with primary anatomic structures in intact corpses, but become very hard in parted bodies especially after a natural disaster, traffic accidents, war, terror and bombing in which people are mutilated and become unrecognizable(Nagesh \& Kumar, 2006).

In these situations, the primary aim of investigation is to determine the age, sex, race and physical features, document trauma and determine the cause of death of the victim. In addition, an attempt is made to determine how long the bones have been exposed to the environment (Cordeiro et al., 2009).

Alternative methods have been developed to cope with these difficulties using: hand measurements, vertebral column length, leg length and footstep length (Nagesh \& Kumar, 2006).

Anthropometry is highly objective and reliable in the hands of trained anthropometrists. The significance and importance of somatometry, cephalometry and osteometry in the identification of human remains have been described by a new term, 'forensic anthropometry' (Krishan, 2007). 
Sex can likewise be determined from various bones/ skeletal remains. When whole skeleton is available, the sex can be determined with almost 99$100 \%$ accuracy. Among individual bones, pelvis is known to provide the most accurate results in the determination of sex (95\% accuracy), followed by skull (92\% accuracy). Several other bones are also used in sex determination such as the femur, tibia, ulna, radius, vertebrae, sternum, metatarsals and metacarpals etc (Kanchan \& Krishan, 2011). So it was very important to study the anthropometric measures of hand in male and female to determine their difference between both and to determine sex as in cases of parted body.

\section{MATERIAL \& METHODS}

Material: The present study is a cross sectional study that was conducted on 160 adult subjects above 21 years old ( 80 males and 80 females).

And are divided into 2 groups(to study the effect of old age changes):

Group 1: from 21 to 50 year old (80 subject; 40 male and 40 female). The period of adulthood.

Group 2: above 50 year old (80 subject; 40 male and 40 female).

The cases were from the cases come to Kasr el ainy hospitals from all governorates. Oral consent was taken from each case.

Anthropological measurements from right hand, and from their digital prints, were taken to determine sex.

\section{A) Subjects Inclusion Criteria:}

These subjects should fulfill certain criteria for choice: age is above 21 years old (after closure of all epiphysis with shaft of bones), both sexes (male and female), Egyptians.

\section{B) Subjects Exclusion Criteria:}

Subjects below 21 years old, Subjects with definite history of trauma, fracture and orthopedic diseases, any hand operations, Patients with any debilitating diseases as poliomyelitis or rheumatoid diseases, deformity of the vertebral column or limbs, congenital or endocrinological diseases or any disease that causes asymmetry.

\section{Methods:}

Anthropometric measures: Seven anthropometric measurements were taken from right hand using mitutoya digital caliper fig. (1):

Hand breadth (HB) a Distance between the most lateral point on the head of the 2nd metacarpal to the most medial point on the head of the 5 th metacarpal.

Hand length (HL) Distance between the mid-point of the distal transverse crease of the wrist to the most anterior projection of the skin of the middle finger.

Palm length (PL) Distance from the mid-point of the distal transverse crease of the wrist to the proximal flexion crease of the middle finger.

Thumb, index, middle and ring finger length: distance between the proximal flexion creases of the finger to the tip of the respective finger fig (2). 


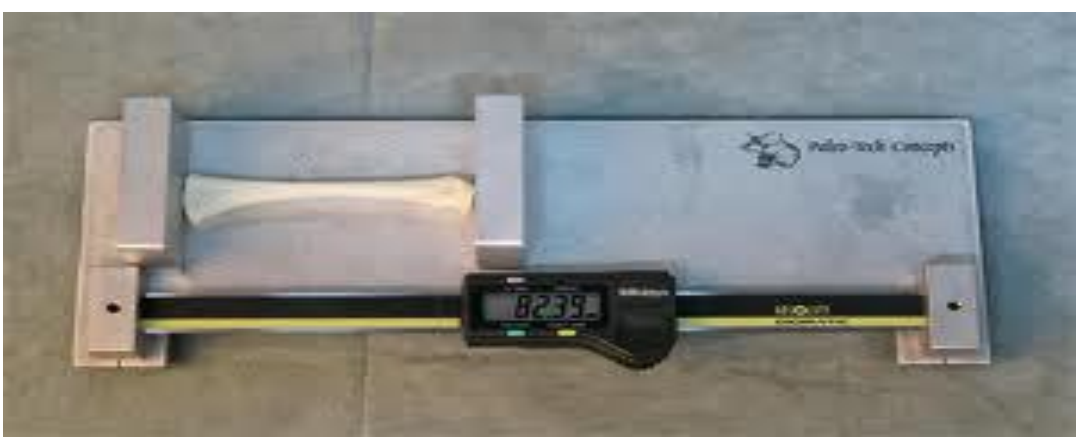

Figure (1): Digital caliper having 0.01 millimeter (mm) sensitivity (Mitutoya).

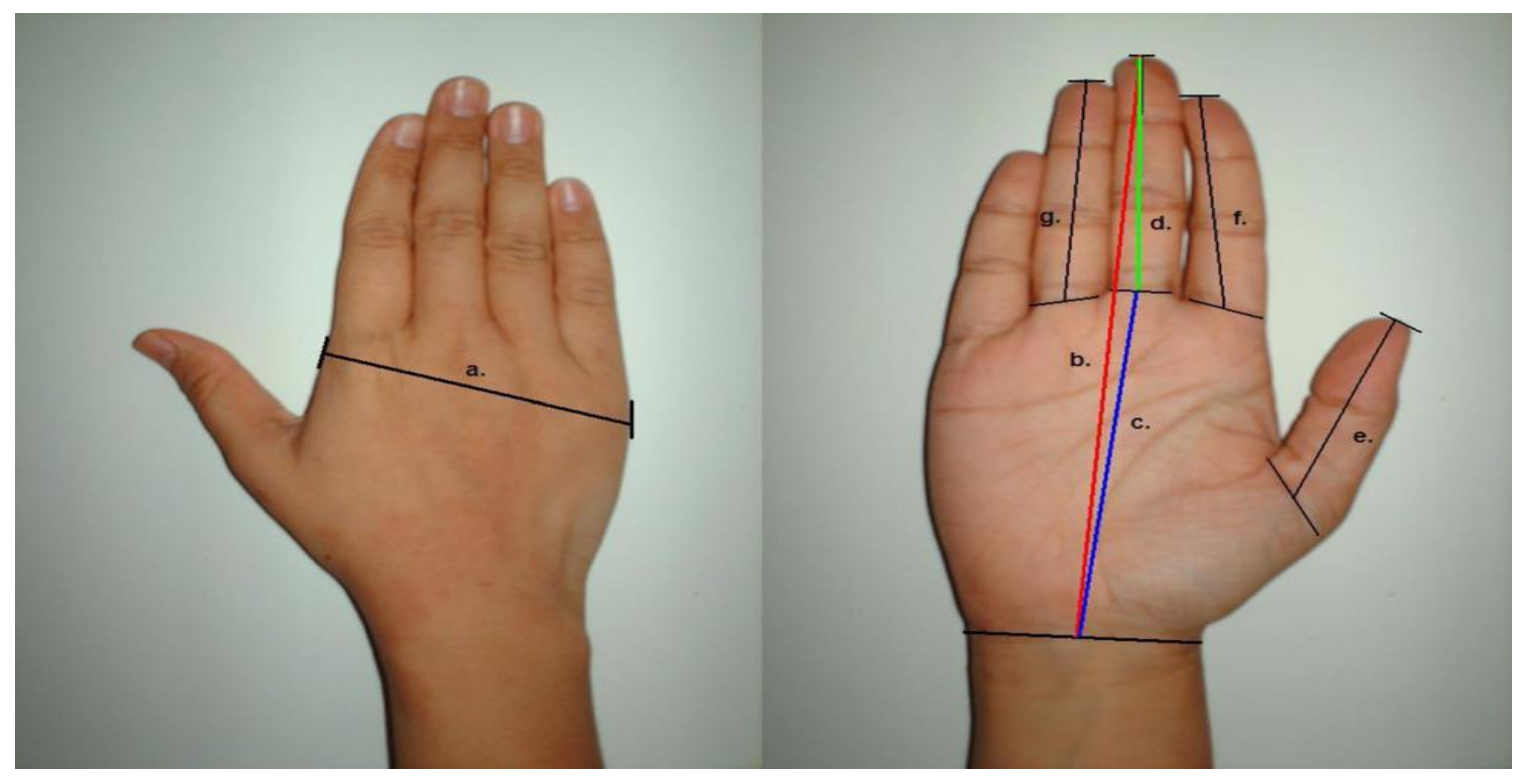

Figure (2): Hand and digital print measurements: (a) hand breadth (HB); (b) hand length (HL); (c) palm length (PL); (d) 3rd digit length (3D); (e) 1st digit length (1D); (f) 2nd digit length (2D); and (g) 4th digit length (4D).

\section{Print parameters:}

The prints were taken from right hand by a highly resolution

samsung camera, 8 megapexil fig. (3), good illumination and from a suitable constant distance $(30 \mathrm{~cm})$, the hand was fully extended (extended fingers and wrist)with flexed elbow. Then to obtain the most accurate approximation of the print, the scanned images were edited using the Photoshop1 on a computer, and the same measures were taken. 

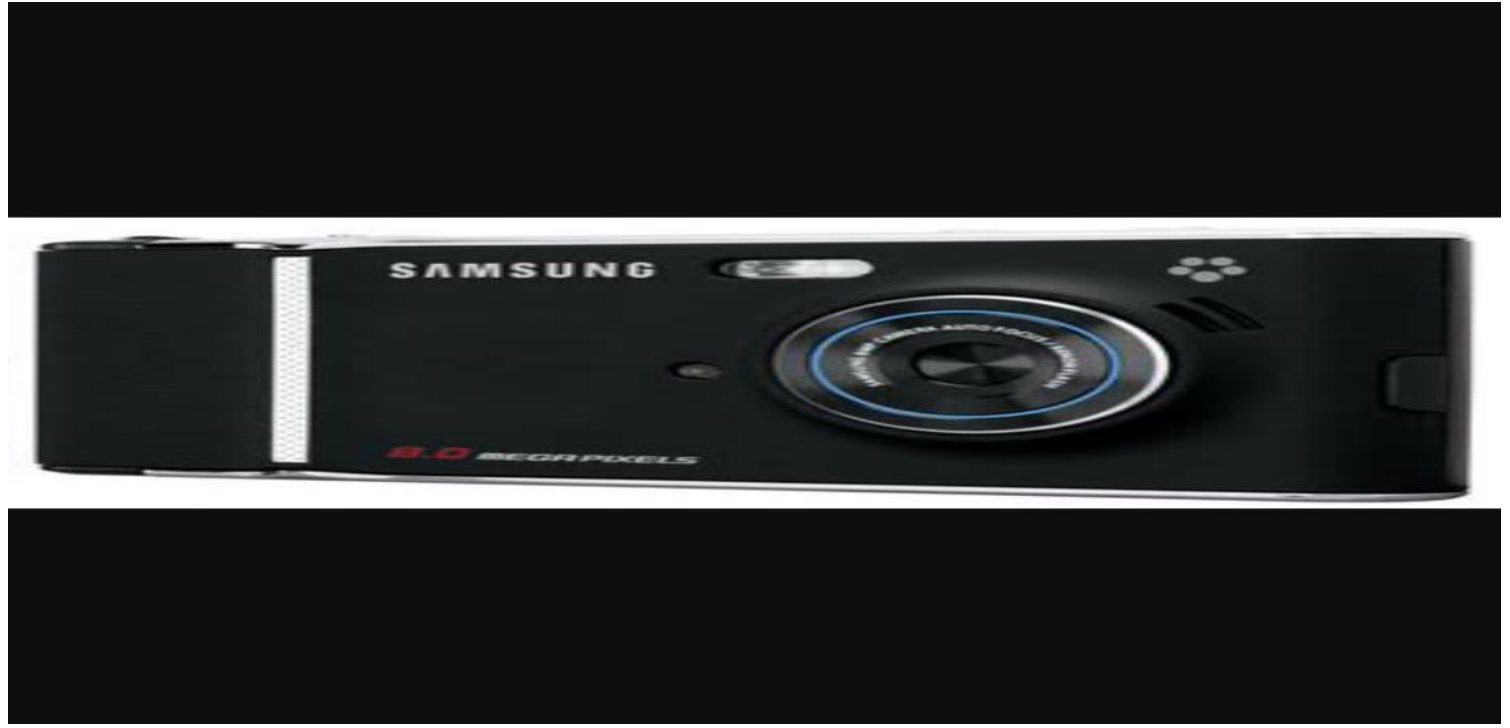

Figure (3):_Samsung 8 megapexil camera.

Statistical analysis:

Data were coded and entered using the statistical package SPSS version 22. Data was summarized using mean, standard deviation, minimum and maximum for quantitative variables and frequencies (number of cases) and relative frequencies (percentages) for categorical variables. . Logistic regression was done to determine sex using measured parameters. P-values less than 0.05 were considered statistically as low significant, less than 0.01 were considered statistically as moderate significant and less than 0.001 were considered statistically as high significant (normal distribution.

\section{RESULTS:}

Table (1): Sex difference regarding right hand anthropometric measures in group-1 (21-50 years)

\begin{tabular}{|c|c|c|c|c|c|}
\hline & \multicolumn{4}{|c|}{ Sex } & \multirow{2}{*}{} \\
\cline { 1 - 4 } Anthropometric measures & \multicolumn{2}{|c|}{ Female } & \multicolumn{2}{c|}{ Male } & \multirow{2}{*}{ P value } \\
\hline (in cm) & Mean & \pm SD & Mean & \pm SD & \\
\hline HB & 7.95 & .44 & $\mathbf{8 . 7 5}$ & .54 & $<0.001$ \\
\hline HL & 17.45 & .84 & 19.19 & 1.07 & $<0.001$ \\
\hline PL & 10.18 & .59 & 11.05 & .67 & $<0.001$ \\
\hline A & $\mathbf{6 . 1 9}$ & .51 & $\mathbf{6 . 7 5}$ & .47 & $<0.001$ \\
\hline B & $\mathbf{6 . 7 6}$ & .47 & 7.51 & .66 & $<0.001$ \\
\hline C & $\mathbf{7 . 2 5}$ & .39 & $\mathbf{8 . 1 3}$ & .53 & $<0.001$ \\
\hline D & $\mathbf{6 . 8 1}$ & .41 & 7.55 & .54 & $<0.001$ \\
\hline
\end{tabular}

-Significance: p-value $\mathbf{\imath} 0.05$

-HB: hand breadth; HL: hand length; PL: palm length; A:thumb length; B: index length; $C$ :middle finger length and D:ring finger length.

-SD: standard deviation. 
Table (1) Showed the mean values between male and female in each measured anthropometric parameter which was highly significant in hand breadth (HB) (7.9 in female increased to 8.75 in male), hand length (HL) (17.45 in female increased to 19.19 in male) , palm length (PL) (10.18 in female increased to 11.05 in male), thumb finger(A) $(6.19$ in female increased to 6.75 in male), index(B) (6.76 in female increased to 7.51 in male), middle finger (C) (7.25 for female increased to 8.13 in male) and ring(D)) length (6.81 for female increased to 7.55 in male).

Table (2): Sex difference in digital right hand print parameters in group-1 (21-50 years)

\begin{tabular}{|c|c|c|c|c|c|}
\hline \multirow{3}{*}{$\frac{\text { Print parameter }}{(\text { in } \mathrm{cm})}$} & \multicolumn{4}{|c|}{ Sex } & \multirow{3}{*}{$P$ value } \\
\hline & \multicolumn{2}{|c|}{ Female } & \multicolumn{2}{|c|}{ Male } & \\
\hline & Mean & \pm SD & Mean & \pm SD & \\
\hline HPB & 5.44 & .78 & 5.70 & .65 & 0.108 \\
\hline HPL & 13.13 & 1.71 & 13.77 & 1.83 & 0.109 \\
\hline PPL & 7.67 & .94 & 7.87 & 1.04 & 0.359 \\
\hline $\mathbf{A P}$ & 3.92 & .59 & 4.26 & .73 & 0.025 \\
\hline BP & 4.88 & .79 & 5.16 & .75 & 0.105 \\
\hline $\mathbf{C P}$ & 5.46 & .85 & 5.90 & .85 & 0.025 \\
\hline DP & 4.87 & .83 & 5.39 & .73 & 0.004 \\
\hline
\end{tabular}

-Significance: $p$-value $<0.05$.

-HPB: hand print breadth; HPL: hand print length; PPL: palm print length; AP: thumb print length; BP: index print length; CP: middle finger print length and DP: ring finger print length.

-SD: standard deviation.

Table (2) showed the difference between male and female RT hand in each measured parameter in RT hand However, there was a moderate significant difference with increased mean in male than female for ring finger print length (DP) was 4.87 in female increasing to 5.39 in male. Moreover, low significant difference was found for thumb length (AP) and middle finger length (CP), while nonsignificant difference was noted for (HPB), HPL and PPL. 
Table (3): Sex difference in right hand anthropometric measures in group-2 (more than 50 years)

\begin{tabular}{|c|c|c|c|c|c|}
\hline & \multicolumn{4}{|c|}{ Sex } & \multirow{2}{*}{ P value } \\
\cline { 1 - 4 } $\begin{array}{c}\text { Anthropomertic measures } \\
\text { (in cm) }\end{array}$ & \multicolumn{2}{|c|}{ Female } & \multicolumn{2}{c|}{ Male } & \\
\hline & Mean & $\mathbf{\pm S D}$ & Mean & $\mathbf{\pm S D}$ & \\
\hline HB & 7.98 & .39 & 8.71 & .66 & $<0.001$ \\
\hline HL & 17.56 & .80 & 19.20 & 1.01 & $<0.001$ \\
\hline PL & 10.15 & .51 & 11.15 & .75 & $<0.001$ \\
\hline A & 6.21 & .45 & 6.66 & .57 & 0.001 \\
\hline B & 6.83 & .46 & 7.24 & .51 & 0.002 \\
\hline C & 7.43 & .44 & 8.00 & .53 & $<0.001$ \\
\hline D & 6.95 & .40 & 7.45 & .43 & $<0.001$ \\
\hline
\end{tabular}

-Significance: p-value $\mathbf{< 0 . 0 5}$.

-HB: hand breadth; HL: hand length; PL:palm length; A:thumb length; B: index length; C:middle finger length and D:ring finger length.

-SD: standard deviation.

Table (3) showed the mean values between male and female in each measured anthropometric parameter. There was a highly significant difference in the measures of hand breadth (HB) (7.98 in female increased to 8.71 in male), hand length (HL) (17.56 in female increased to 19.2 in male), palm length (PL) (10.15 in female increased to 11.15 in male), thumb finger(A) $(6.21$ in female increased to 6.66 in male), middle finger (C) ( 7.43 for female increased to 8.00 in male) and ring (D)) length ( 6.95 for female increased to 7.45 in male). While index finger (b) showed moderately significant difference.

Table (4): Sex difference in digital right hand print parameters in group-2 (more than 50 years)

\begin{tabular}{|c|c|c|c|c|c|}
\hline \multirow{3}{*}{$\begin{array}{c}\begin{array}{c}\text { Print } \\
\text { parameter }\end{array} \\
\text { (in } \mathrm{cm})\end{array}$} & \multicolumn{4}{|c|}{ Sex } & \multirow{3}{*}{$P$ value } \\
\hline & \multicolumn{2}{|c|}{ Female } & \multicolumn{2}{|c|}{ Male } & \\
\hline & Mean & \pm SD & Mean & \pm SD & \\
\hline HPB & 5.93 & .70 & 5.78 & .67 & 0.389 \\
\hline HPL & 13.63 & 1.35 & 13.96 & 2.03 & 0.471 \\
\hline PPL & 7.95 & .75 & 7.90 & 1.07 & 0.831 \\
\hline AP & 4.15 & .61 & 4.27 & .66 & 0.492 \\
\hline BP & 5.14 & .59 & 5.14 & .75 & 0.988 \\
\hline CP & 5.68 & .73 & 5.79 & .87 & 0.605 \\
\hline DP & 5.34 & .68 & 5.37 & .81 & 0.882 \\
\hline
\end{tabular}

-Significance: p-value $₫ 0.05$.

-HPB: hand print breadth; HPL: hand print length; PPL: palm print length; AP: thumb print length; BP: index print length; CP: middle finger print length and DP: ring finger print length.

-SD: standard deviation. 
Table (4) Showed no significant means of all measures in males were difference for all measures although the higher in males than females.

Table (5): Logistic regression to detect sex in group-1 (21-50 years) using anthropometric measures

\begin{tabular}{|c|c|c|}
\hline $\begin{array}{c}\text { Anthropometric measures } \\
\text { (in cm) }\end{array}$ & N & P value \\
\hline HB & .983 & .461 \\
\hline HL & $\mathbf{- 4 . 8 2 2 -}$ & .803 \\
\hline PL & 5.891 & .760 \\
\hline A & .652 & .617 \\
\hline B & $-2.698-$ & .109 \\
\hline C & 10.639 & .589 \\
\hline D & $-1.980-$ & .393 \\
\hline
\end{tabular}

-Significance: p-value $\mathbf{\imath} 0.05$.

-HB: hand breadth; HL: hand length; PL:palm length; A:thumb length; B: index length; $C$ :middle finger length; D:ring finger length and $\mathrm{N}$; constant.

Logistic regression equation to determine sex in group 1 using anthropometric measures:

Sex

$=-61.987+0.983$ HB- 4.822 HL+

5.891 PL+ 0.652 A- 2.698 B +10.639 C $-1.98 \mathrm{D}$.
To estimate the gender by right hand measurements, Logistic regression analysis was performed. The limit value for logistic regression model equation was 0.50 . The values less than 0.50 were evaluated as female, and values more than 0.50 were evaluated as male.

Table (6):_Percentage correct prediction of logistic regression to detect sex in group-1 (21-50 years) using anthropometric measures

\begin{tabular}{|c|c|c|c|c|}
\hline \multirow{3}{*}{\multicolumn{2}{|c|}{ Observed }} & \multicolumn{3}{|c|}{ Predicted } \\
\hline & & \multicolumn{2}{|c|}{ Sex } & \multirow{2}{*}{$\begin{array}{c}\text { Percentage } \\
\text { Correct }\end{array}$} \\
\hline & & Female & Male & \\
\hline \multirow{2}{*}{ Sex } & Female & 37 & 3 & 92.5 \\
\hline & Male & 4 & 36 & 90.0 \\
\hline \multicolumn{2}{|c|}{ Overall Percentage } & & & 91.2 \\
\hline
\end{tabular}

In the stepwise analysis of the hand anthropometric measures; crossvalidated sex classification accuracy of this equation was $91.2 \%$. It predicted
37 cases from 40 female cases as female $(92.5 \%)$, and predicts 36 cases from 40 male cases as male. 
Table (7): Logistic regression to detect sex in group-2 (more than 50 years) using anthropometric measures

\begin{tabular}{|c|c|c|}
\hline $\begin{array}{c}\text { Anthropometric measures } \\
\text { (in cm) }\end{array}$ & N & P value \\
\hline HB & $\mathbf{2 . 3 7 7}$ & $\mathbf{. 0 3 5}$ \\
\hline HL & $\mathbf{9 . 6 4 0}$ & $\mathbf{. 5 2 4}$ \\
\hline PL & $\mathbf{- 7 . 2 4 8 -}$ & $\mathbf{. 6 3 6}$ \\
\hline A & $\mathbf{. 3 4 2}$ & $\mathbf{. 7 6 5}$ \\
\hline B & $\mathbf{- 3 . 0 8 5 -}$ & $\mathbf{. 1 0 5}$ \\
\hline C & $\mathbf{- 6 . 2 7 9 -}$ & $\mathbf{. 6 7 9}$ \\
\hline D & $\mathbf{. 7 7 1}$ & $\mathbf{. 6 8 5}$ \\
\hline
\end{tabular}

-Significance: p-value $<0.05$.

-HB: hand breadth; HL: hand length; PL:palm length; A:thumb length; B: index length; C:middle finger length and D:ring finger length and N:constant

Logistic regression equation to determine sex in group-2 using anthropometric measures:

The limit value for logistic regression model equation was 0.50 . The values less than 0.50 were evaluated as female

Sex

$=\quad-48.541+2.377 \mathrm{HB}+9.640 \mathrm{HL}-$ and values more than 0.50 were

7.248PL+0.342A-3.085B-

evaluated as male.

$6.279 \mathrm{C}+0.771 \mathrm{D}$

Table (8): Percentage correct prediction of logistic regression to detect sex group-2 (more than 50 years) using anthropometric measures

\begin{tabular}{|c|c|c|c|c|}
\hline \multirow{2}{*}{\multicolumn{2}{|c|}{ Observed }} & \multirow{2}{*}{\multicolumn{3}{|c|}{ Predicted }} \\
\hline & & & & \\
\hline & & \multicolumn{2}{|c|}{ Sex } & \multirow{2}{*}{$\begin{array}{l}\text { Percentage } \\
\text { Correct }\end{array}$} \\
\hline & & female & Male & \\
\hline \multirow[t]{2}{*}{ Sex } & Female & 36 & 4 & 90.0 \\
\hline & Male & 5 & 35 & 87.5 \\
\hline \multicolumn{2}{|c|}{ Overall Percentage } & & & $\mathbf{8 8 . 7 5}$ \\
\hline
\end{tabular}

In the stepwise analysis of the hand anthropometric measures; crossvalidated sex classification accuracy of this equation was $88.75 \%$. Predicted
36 cases from 40 female cases were female $(90 \%)$ and 35 cases from 40 male cases were male $(87.5 \%)$. 
Table (9): Logistic regression to detect sex using digital print parameters in group-1 (21-50 years)

\begin{tabular}{|c|c|c|}
\hline & $\mathbf{N}$ & $\mathbf{P}$ value \\
\hline HPB & $\mathbf{. 1 4 0}$ & $\mathbf{. 8 3 1}$ \\
\hline HPL & $\mathbf{9 . 3 6 4}$ & $\mathbf{. 5 0 9}$ \\
\hline PPL & $\mathbf{- 9 . 2 0 4 -}$ & $\mathbf{. 5 1 5}$ \\
\hline AP & $\mathbf{1 . 3 3 5}$ & .059 \\
\hline BP & $\mathbf{- 4 . 0 1 8 -}$ & .023 \\
\hline CP & $\mathbf{- 9 . 9 6 4 -}$ & $\mathbf{. 4 8 0}$ \\
\hline DP & $\mathbf{3 . 7 5 2}$ & .013 \\
\hline
\end{tabular}

- Significance: p-value $<0.05$.

-HPB: hand print breadth; HPL: hand print length; PPL: palm print length; AP: thumb print length; BP: index print length; CP: middle finger print length; DP: ring finger print length and $\mathrm{N}$ constant

Logistic regression equation to determine sex in group 1 using print measures:

Sex

$=\quad-14.775+0.140 \mathrm{HBP}+9.364 \mathrm{HLP}-$

9.204PLP+1.335AP-4.018BP-

9.964CP+3.752DP.
The limit value for logistic regression model equation was 0.50 . The values less than 0.50 were evaluated as female and values more than 0.50 were evaluated as male.

Table (10):_Percent correct prediction by logistic regression to detect sex using digital print parameters in group-1 (20-50 years).

\begin{tabular}{|c|c|c|c|c|}
\hline \multirow{3}{*}{\multicolumn{2}{|c|}{ Observed }} & \multicolumn{3}{|c|}{$\begin{array}{l}\text { Predicted } \\
\end{array}$} \\
\hline & & \multicolumn{2}{|c|}{ Sex } & \multirow{2}{*}{$\begin{array}{l}\text { Percentage } \\
\text { Correct }\end{array}$} \\
\hline & & Female & Male & \\
\hline \multirow{2}{*}{ Sex } & Female & 32 & 8 & 80.0 \\
\hline & Male & 9 & 31 & 77.5 \\
\hline \multicolumn{2}{|c|}{ Overall Percentage } & & & 78.8 \\
\hline
\end{tabular}

In the stepwise analysis of the hand print parameters ; cross-validated sex classification accuracy of this equation is $78.8 \%$ as it predict 32 cases from 40 female cases are female $(80 \%)$ and predict 31 cases from 40 male cases are male $(77.5 \%)$. 
Table (11): Logistic regression to detect sex using digital print parameters in group-2 (more than 50 years)

\begin{tabular}{|c|c|c|}
\hline & N & P value \\
\hline HPB & $-.866-$ & .166 \\
\hline HPL & 2.864 & 1.000 \\
\hline PPL & $-2.766-$ & 1.000 \\
\hline AP & 1.392 & .116 \\
\hline BP & $-2.588-$ & .124 \\
\hline CP & $-.462-$ & 1.000 \\
\hline DP & $-.879-$ & .563 \\
\hline
\end{tabular}

- Significance: p-value $\mathbf{0 . 0 5}$.

-HPB: hand print breadth; HPL: hand print length; PPL: palm print length; AP: thumb print length; BP: index print length; CP: middle finger print length ; DP: ring finger print length and $\mathrm{N}$ : constant.

Logistic regression equation to determine sex in group-2 using anthropometric measures:

Sex

$=\quad-2.280-.866 \mathrm{HPB}+2.864 \mathrm{HPL}-$

2.766PPL+1.392AP-2.588BP-.462CP-

$.879 \mathrm{DP}$.
The limit value for logistic regression model equation was 0.50 . The values less than 0.50 were evaluated as female and values more than 0.50 were evaluated as male.

Table (12): Percentage correct prediction by logistic regression to detect sex using digital print parameters in group-2 (more than 50 years)

\begin{tabular}{|c|c|c|c|c|}
\hline \multirow{3}{*}{\multicolumn{2}{|c|}{ Observed }} & \multicolumn{3}{|c|}{ Predicted } \\
\hline & & \multicolumn{2}{|c|}{ Sex } & \multirow{2}{*}{$\begin{array}{l}\text { Percentage } \\
\text { Correct }\end{array}$} \\
\hline & & Female & Male & \\
\hline \multirow[t]{2}{*}{ Sex } & Female & 25 & 15 & 62.5 \\
\hline & Male & 13 & 27 & 67.5 \\
\hline \multicolumn{2}{|c|}{ Overall Percentage } & & & 65.0 \\
\hline
\end{tabular}

In the stepwise analysis of the hand anthropometric measures ;crossvalidated sex classification accuracy of this equation was $65 \%$.It predicted 25 cases from 40 female cases were female $(62.5 \%)$, and 27 cases from 40 male cases were male $(67.5 \%)$.

\section{DISCUSSION}

As regards sex difference the current study, showed highly statistically significant differences of all anthropometric hand measures. This study showed significantly higher measures in males. This result agrees with Okunribido (2000), in western Nigeria, Rastogi et al. (2008), concluded that hand dimensions were statistically significantly correlated among males and females.

This result can be explained by the fact that as the age of puberty being two years later in males as compared to females giving them additional time for 
growth. Besides, it is a known fact that body physique is influenced by climatic, hereditary, nutritional, and racial factors. The development and expression of human sexual dimorphism (expressed as absolute differences in size, shape and behavior) are well documented in the literature, and are known to arise under the influence of hormonal changes around puberty (Agnihotri et al., 2008). Sexual dimorphism can be regarded as primarily and secondary sexual characteristics. However, it is postulated that, "Sexual dimorphism can only be acquired through more rapid male growth if nutritional resources are adequate.". This is potential plausible reason that there is global populational variability in the expression of sexual dimorphism (Case \& Ross, 2007).

To determine sex from the anthropometric measures in both groups, logistic regression was done to create regression equation. The accuracy of sex determination by this equation was $91 \%$ and $88.75 \%$ respectively in young and old age groups. The accuracy is less in older group, perhaps for the degenerative changes in hand and feet bones. This degree of accuracy approximates that of whole bones that characterize sex as pelvis $(95 \%)$ and skull

$(92 \%)$

(Kanchan \& Krishan, 2011).

The work of Jowaheer

\&Agnihotri (2011) demonstrated that logistic regression sex was accepted with an expected accuracy of above 90\%. Additional support was found by Kanchan \& Rastogi (2009) who showed expected accuracies above $85 \%$ using logistic regression.

In the current study, there were significant differences between males and females in the mean values of digital print parameters from hand in group-1 (except HB, HL and PL) and in group 2 ,all parameters showed nonsignificant difference.

To determine sex from print parameters in both groups, logistic regression was done to create regression equation. The accuracy of sex determination by this equation was 78.8. $\%$ and $65 \%$ respectively . These results agreed with Ishak et al. (2012) who showed that print parameters were less accurate than the anthropometric measures.

Regarding the comparison between anthropometric method and the digital print method for determination of sex in our study, the anthropometric method was more accurate, because the digital prints are a proxy for real size. However, prints are still an imperfect representation of the actual measures and it is a promising area for future research.

\section{CONCLUSION}

In the current study we have outlined a series of new forensic standards for the estimation of sex in a group of adult Egyptians of both sexes using forensic anthropological methods. The study has successfully evaluated the relationships between sex with anthropometric and print measures. Males had larger hand dimensions than females in both anthropometric and print measures. Logistic regression equations were more accurate for sex determination by using anthropometric measure than digital print measures.

To determine sex in cases (21-50 years) using anthropometric measures the following equation used 
Sex

$=\quad-48.541+2.377 \mathrm{HB}+9.640 \mathrm{HL}-$

7.248PL+0.342A-3.085B-

6.279C+0.771D.

To determine sex in cases (more than 50 years) using anthropometric measures the following equation used

Sex

$=\quad-48.541+2.377 \mathrm{HB}+9.640 \mathrm{HL}-$

7.248PL+0.342A-3.085B-

$6.279 \mathrm{C}+0.771 \mathrm{D}$.

To determine sex in cases (21-50 years) using digital print method, the following equation used

Sex

$=\quad-14.775+0.140 \mathrm{HBP}+9.364 \mathrm{HLP}-$

9.204PLP+1.335AP-4.018BP-

9.964CP+3.752DP.

To determine sex in cases (more than 50 years) using digital print measures, the following equation used

Sex

$=\quad-2.280-.866 \mathrm{HPB}+2.864 \mathrm{HPL}-$

2.766PPL+1.392AP-2.588BP-.462CP.879DP.

The limit value for logistic regression model equation was 0.50 . The values less than 0.50 were evaluated as female and values more than 0.50 were evaluated as male.

\section{RECOMMENDATIONS}

Using the anthropometric measurements in determination of sex from hand is very accurate as the print method is less accurate, future research works are required to increase the accuracy of print method.

\section{REFERENCES}

Agnihotri, A.K.; Agnihotri, S., Jeebun, N. and Googoolye, K. (2008): Prediction of stature using hand dimensions. J. For. Leg. Med.;15 : 479482

Case, D.T. and Ross, A.H. (2007): Sex determination from hand and foot bone lengths. J. For. Sci.; 52 : 264-270.

Cordeiro, C.; Wasterlain, S., Cunha, E. and Vieira, D.N. (2009): Predicting adult stature from metatarsal length in a Portuguese population. For. Sci. Inter., 193(1-3), 131e1-131e4.

Ishak, N.; Hemy, N. and Franklin, D. (2012): Estimation of sex from hand and handprint dimensions in a Western Australian population. For. Sci. Inter.; 221 : 154.e1-154.e6.

Jowaheer, V. and Agnihotri, A.K. (2011): Sex identification on the basis of hand and foot measurements in Indo-Mauritian population - a model based approach, J. For. Leg. Med.; 18 : 173-176.

Kanchan, T. and Krishan, $K$. (2011): Anthropometry of hand in sex determination of dismembered remains-A review of literature. J For. Leg. Med .;18: 14-17.

Kanchan, T. and Rastogi, T. (2009): Sex determination from hand dimensions of North and South Indians, J. For.Sci.; 54 : 546-550.

Krishan, K. (2007): Anthropometry in forensic medicine and forensic science-forensic anthropometry, Int. J. For. Sci.; 2(1): 22-38.

Nagesh, K.R. and Kumar, G.P. (2006): Estimation of stature from vertebral column length in South Indians, Leg. Med.; 8 : 269-272.

Okunribido, O.O. (2000): A survey of hand anthropometry of female rural farm workers in Ibadan, 
western Nigeria. Ergonomics; 43 : 282292.

Rastogi, P.; Nagesh, K.R. and Yoganarasimha, K. (2008):
Estimation of stature from hand dimensions of north and south Indians J. Forensic Sci \& crim.; 2(2): 2-11. 


\section{الملخص العربي}

\section{دراسة انثرويومترية على اليا وبصماتها الرقمية لتحديد الجنس فى عينة من المصريين}

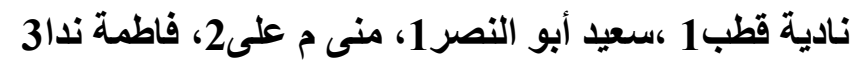

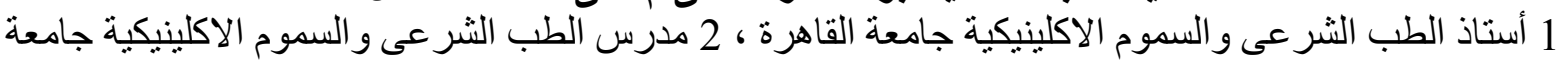

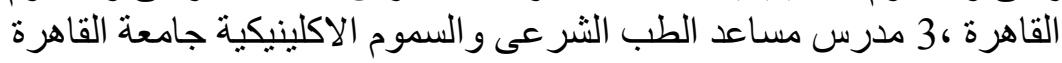

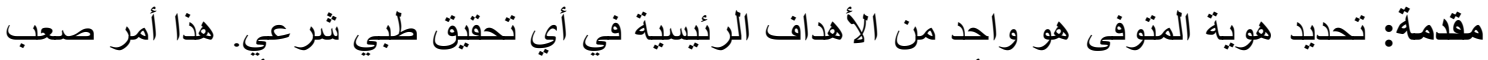

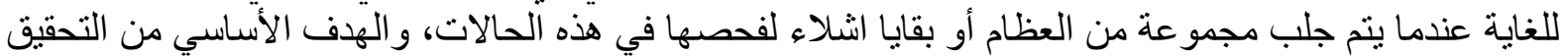

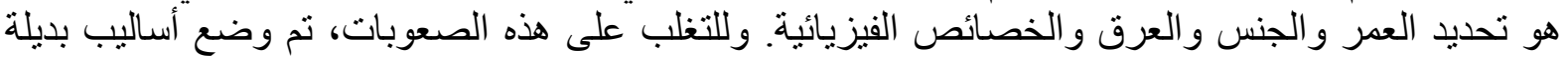

الههف من هذه الدراسة: هووضع صيغ لتقدير الجنس من خلال القياسات الانثروبومترية مع البصمات جديدة.

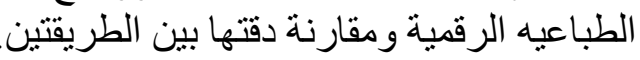

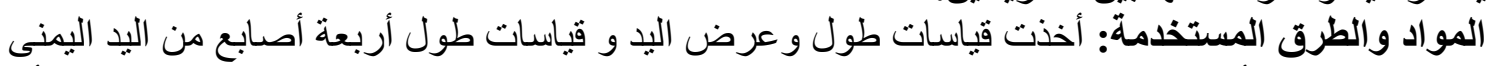

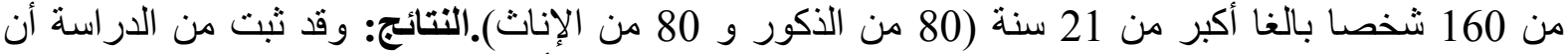

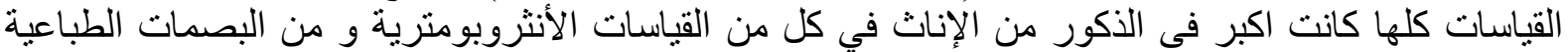

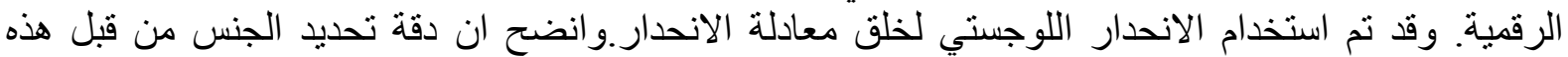

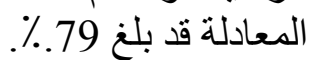
الاستنتاج: تم الحصول على الإنى الصيغ عن طريق تحليل الانحدار اللوجستية كل منها. وكانت النتائج

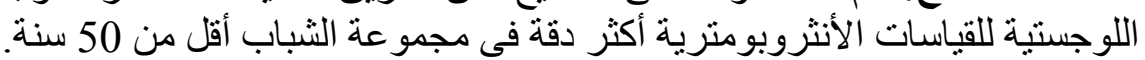

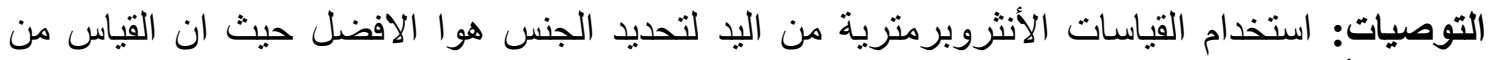
البصمة الرقميه أقل دقة. مطلوب العمل البحثى فى هذا المجال زيادة دقة البصمة الرقئة الرقية. 